\title{
A Study of the Intrarenal Recycling of Urea in the Rat with Chronic Experimental Pyelonephritis
}

\author{
Richard M. Gilbert, Herbert Weber, Louise Turchin, LeON G. Fine, \\ JaCQues J. Bourgoignie, and NeAL S. BRICKER
}

From the Kidney and Electrolyte Section, Division of Nephrology, Department of Medicine, Albert Einstein College of Medicine, Bronx, New York 10461

\begin{abstract}
A в S T R A C T The concentrating ability of the kidney was studied by clearance and micropuncture techniques and tissue slice analyses in normal rats with two intact kidneys (intact controls), normal rats with a solitary kidney (uninephrectomized controls), and uremic rats with a single pyelonephritic kidney. Urinary osmolality after water deprivation for $24 \mathrm{~h}$ and administration of antidiuretic hormone was $2,501 \pm 217$ and $2,874 \pm 392 \mathrm{mosmol} / \mathrm{kg} \mathrm{H}_{2} \mathrm{O}$ in intact and uninephrectomized control rats, respectively, and $929 \pm 130 \mathrm{mosmol} / \mathrm{kg} \mathrm{H}_{2} \mathrm{O}$ in pyelonephritic rats $(P<0.001$ compared to each control group). Fractional water reabsorption and concentrating ability were significantly decreased in the pyelonephritic group, and, to achieve an equivalent fractional excretion of urea, a greater fractional excretion of water was required in the pyelonephritic rats than in the control rats.

Whole animal glomerular filtration rate was 1.57 $\pm 0.19 \mathrm{ml} / \mathrm{min}$ and $1.39 \pm 0.18 \mathrm{ml} / \mathrm{min}$ in intact and in uninephrectomized controls, respectively, and 0.30 $\pm 0.07 \mathrm{ml} / \mathrm{min}$ in pyelonephritic rats $(P<0.001 \mathrm{com}$ pared to each control group). Single nephron glomerular filtration rate was $35.6 \pm 3.8 \mathrm{nl} / \mathrm{min}$ in intact control rats and was significantly increased $(P<0.05)$ in both uninephrectomized $(88.0 \pm 10.8 \mathrm{nl} / \mathrm{min})$ and pyelonephritic rats $(71.5 \pm 14.4 \mathrm{nl} / \mathrm{min})$.
\end{abstract}

A preliminary report of this work has been published in Abstracts Am. Soc. Nephrol., 8: 62, 1975.

Requests for reprint orders should be addressed to Dr. Gilbert, Renal Division, Department of Medicine, Montefiore Hospital, Bronx, N. Y. 10467. Dr. Fine's, Dr. Bourgoignie's, and Dr. Bricker's present address is: Department of Medicine, University of Miami School of Medicine, P. O. Box 520875Biscayne Annex, Miami, Fla. 33152.

Received for publication 12 January 1976 and in revised form 28 June 1976.
In all groups fractional water delivery and fractional sodium delivery were closely comparable at the end of the proximal convoluted tubule and at the beginning of the distal convoluted tubule. In contrast, fractional urea delivery out of the proximal tubule was greater in the intact control group $(73 \pm 8 \%)$ than in either the uninephrectomized $(52 \pm 2 \%)$ or the pyelonephritic group $(53 \pm 3 \%)(P<0.005)$. Fractional urea delivery at the early part of the distal tubule increased significantly to $137 \pm 11 \%$ and $93 \pm 6 \%$ of the filtered load in intact control and uninephrectomized control rats, respectively $(P<0.001$ compared to the late proximal values of each group), but failed to increase significantly in pyelonephritic rats $(65 \pm 13 \%)$, indicating interruption of the normal recycling of urea in the latter group.

Analysis of tissue slices demonstrated a rising corticopapillary gradient for total tissue water solute concentration as well as for tissue water urea concentration in both groups of control rats. In contrast, the pyelonephritic animals exhibited no similar gradients from cortex to papilla.

These data indicate that the pyelonephritic kidney fails to recycle urea and accumulate interstitial solute. The latter must inevitably lead to a concentrating defect.

\section{INTRODUCTION}

Failure to concentrate the urine maximally is characteristic of end-stage renal disease (1). Several mechanisms have been proposed to explain this functional impairment (2). These include: $(a)$ anatomic disruption of the inner medullary regions by scarring and inflammation; $(b)$ the obligatory solute diuresis dictated by the requirement to maintain external balance for a variety of different solutes despite fewer 
nephrons; (c) impaired transport of sodium chloride by the ascending limb of the loop of Henle; $(d)$ reduced responsiveness to antidiuretic hormone $(\mathrm{ADH})^{1}$; and (e) "washout" of the medullary solute pool as a result of increased medullary plasma flow. While each of these hypotheses has certain attractive features, none is entirely satisfactory: $(a)$ not all chronic renal diseases produce primary or preferential histopathologic changes within the inner medulla, yet all are associated with a concentrating defect $(1,2)$; the maximum urine-toplasma osmolal ratio $\left[(\mathrm{U} / \mathrm{P})_{\text {osm }}\right]$ remains depressed even when values are corrected for the effect of the increased solute excretion rate (per nephron) on urinary osmolality $(3,4)$. (c) The ability to dilute the urine, also dependent upon transport of $\mathrm{NaCl}$ by the ascending limb of the loop of Henle, persists long after the concentrating defect becomes overtly manifest (4). (d) The existing evidence either for or against a change in responsiveness to $\mathrm{ADH}$ is inconclusive $(5,6)$. (e) Finally, no compelling data either support or contradict the thesis that a medullary washout results from increased medullary plasma flow in chronic renal insufficiency (7).

Recently the role of the intrarenal "recycling" of urea in the normal concentrating process has been reemphasized $(8,9)$. Urea constitutes a major fraction of the total pool of osmotically active particles in the inner medulla of the kidney and thus contributes importantly to the maintenance of medullary hypertonicity. The latter, in turn, is crucial for the generation of a hyperosmotic urine by promoting the abstraction of free water from the inner medullary and papillary collecting ducts, and may possibly play a role in the reabsorption of sodium chloride from the thin ascending limb of the loop of Henle $(8,10)$.

The present studies examine the concentrating defect in rats with experimentally induced chronic pyelonephritis utilizing clearance, micropuncture, and tissue homogenate techniques. Particular attention has been directed to the intrarenal movements of urea and to the corticopapillary concentration gradients for urea and total solutes. The data show an interruption in the normal intrarenal urea cycle that eventuates in the obliteration of the normal corticopapillary concentration gradient for sodium chloride and urea. This failure to accumulate medullary solute could play an important role in the concentrating defect in chronic renal disease.

\footnotetext{
${ }^{1}$ Abbreviations used in this paper: $\mathrm{ADH}$, antidiuretic hormone; FE, fractional excretion; GFR, glomerular filtration rate; SNGFR, single nephron GFR; $\mathrm{T}_{\mathrm{H}_{2} \mathrm{O}}^{\mathrm{O}} / \mathrm{GFR}$, fractional free water reabsorption; $(\mathrm{TF} / \mathrm{P})_{\mathrm{In}},(\mathrm{TF} / \mathrm{P})_{\mathrm{Na}},(\mathrm{TF} / \mathrm{P})_{\text {urea }}$, $(\mathrm{TF} / \mathrm{P})_{\text {osm }}$, ratio of tubular fluid to plasma concentrations of inulin, sodium, urea, and total solute; $U_{\max }$, maximal urinary osmolality; $(\mathrm{U} / \mathrm{P})_{\text {osm }}$, urine to plasma osmolal ratio.
}

\section{METHODS}

Data were obtained on 78 female Sprague-Dawley rats (Taconic Farms, Inc., Germantown, N.Y.) weighing 205298 g. 47 control experiments were performed on 27 intact rats and 20 rats subjected to unilateral nephrectomy. 31 experiments were performed on pyelonephritic animals. Unless otherwise specified, all animals were fed standard rat chow (Teklad Mouse and Rat Diet, Teklad Mills, The Mogul Corp., Winfield, Iowa) and had free access to water.

Preparation of the pyelonephritic animals. Unilateral pyelonephritis was induced in 49 rats by a modification of the technique described by Lubowitz et al. (11). After the animal was lightly anesthetized with ether, the left kidney was exposed through a posterior subcostal incision and punctured to a depth of approximately $5 \mathrm{~mm}$ some $15-20$ times with a heated 23 gauge electrocautery needle. The kidney was then punctured an additional 20 times with a 26 gauge hypodermic needle dipped repeatedly in nutrient broth containing a turbid culture of $E$. coli isolated from a patient with a urinary tract infection and incubated overnight in the broth without aeration. Finally, $0.1 \mathrm{ml}$ of the broth culture was injected directly into the parenchyma of the kidney and $0.5 \mathrm{ml}$ of the same culture was administered intravenously via a tail vein. The kidney was then washed with isotonic saline, and replaced in its fossa and the skin incision was closed. $2 \mathrm{wk}$ after this procedure, the animals underwent a right nephrectomy.

For the first few days after induction of unilateral pyelonephritis the animals exhibited gross hematuria but otherwise remained alert and appeared clinically well. However, after right nephrectomy, they developed clinical manifestations of uremia including lethargy, failure to gain weight, loss of skin turgor, and failure to regrow hair. Of the original group of 49 animals, 18 died before they could be studied.

Grossly, the kidneys were contracted and scarred. The internal architecture was moderately distorted. Microscopically, the changes included "thyroidization" of tubules, extensive interstitial infiltration of inflammatory cells, and scar formation. The glomeruli appeared normal (Fig. 1). Experiments on the 31 surviving pyelonephritic rats and on the uninephrectomized control rats were performed from 2 to $4 \mathrm{wk}$ after removal of the right kidney.

Studies of maximal urinary concentrating ability $\left(U_{\max }\right)$. $\mathrm{U}_{\max }$ was determined in seven intact and four uninephrectomized controls and in seven pyelonephritic rats, after $24 \mathrm{~h}$ of water and food deprivation. The evening before study, each rat was given a subcutaneous injection of $500 \mathrm{mU}$ ADH in oil (Pitressin, Park, Davis \& Company, Detroit, Mich.) and placed in an individual metabolic cage. Urine was collected under mineral oil for $16 \mathrm{~h}$ to measure osmolality. Water and food were withheld during the collection. Thereafter, the rats had free access to food and water for at least $1 \mathrm{wk}$ before micropuncture studies were performed.

\section{Micropuncture and clearance studies}

Hydropenic animals. The animals in this series of experiments were given a subcutaneous injection of $500 \mathrm{mU}$ ADH in oil and were deprived of food and water $16 \mathrm{~h}$ before the beginning of the micropuncture experiments. On the morning of study the rats were anesthetized with $100 \mathrm{mg} / \mathrm{kg}$ Inactin (Promonta, Hamburg, W. Germany). After a tracheostomy, the rats were placed on a heated board. The rectal temperature was maintained at $37^{\circ} \mathrm{C}$ with a thermistor connected to the heat source. The right external jugular vein 

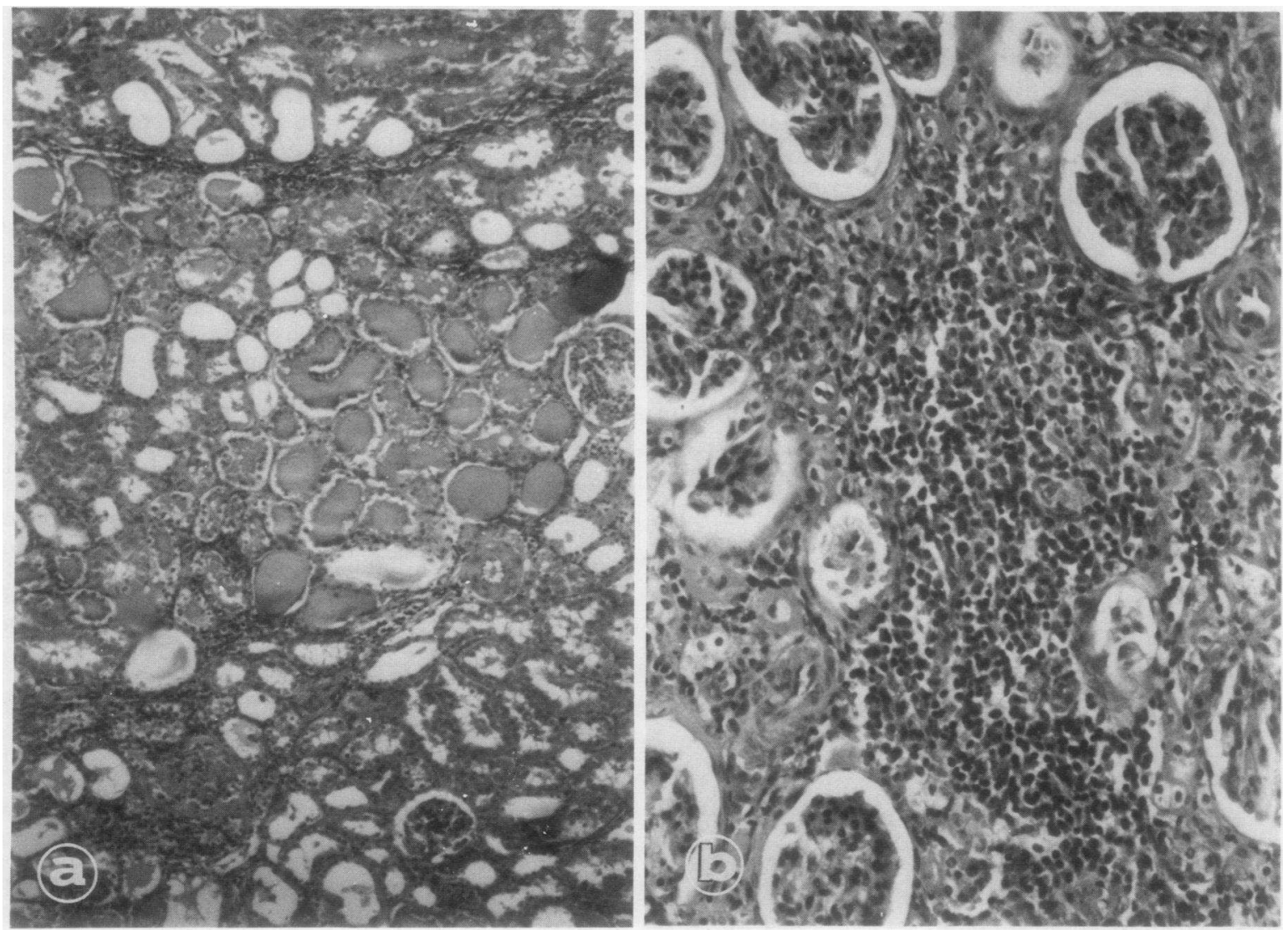

FIGURE 1 a. Low-power $(100 \times)$ view of pyelonephritic kidney. Glomeruli are uninvolved. Tubules are dilated and contain eosinophilic material ("thyroidization"). Interstitial inflammation is also demonstrated. $b$. High-power $(400 \times)$ view of microabscess found in the cortex. The inflammatory process invades the interstitium with chronic inflammatory cells but spares the glomeruli.

and the right femoral artery were cannulated with PE 50 polyethylene tubing (Clay Adams, Div. of Becton, Dickinson and Co., Parsippany, N.J.) for intravenous infusion and monitoring of arterial blood pressure, respectively. The bladder was catheterized with Silastic tubing $(0.037$ inch out-side diameter, 602-135, Dow Corning Corp., Midland, Mich.) The left kidney was exposed through a subcostal incision and gently separated from the perirenal fat and adrenal gland. Special care was taken not to stretch the renal pedicle. Adhesions were carefully lysed. The kidney was then placed in a cotton-padded Lucite cup and bathed in mineral oil maintained at $37^{\circ} \mathrm{C}$.

After the surgical procedure was completed, a priming dose of $200-250 \mu \mathrm{Ci}\left[{ }^{3} \mathrm{H}\right]$ methoxy-inulin and $30 \mu \mathrm{Ci}\left[{ }^{14} \mathrm{C}\right]$ urea (New England Nuclear, Boston, Mass.) in $1.0 \mathrm{ml}$ of a $0.9 \%$ solution of $\mathrm{NaCl}$ was administered intravenously. As previously demonstrated by others $(12)$, the use of $\left[{ }^{14} \mathrm{C}\right]$ urea in these experiments was validated by determining the ratio of $(\mathrm{U} / \mathrm{P})_{\text {urea }}$ by simultaneous isotopic and chemical methods in 11 rats; the mean ratio of isotopically to chemically measured $(\mathrm{U} / \mathrm{P})_{\text {urea }}$ was $1.10 \pm 0.11$, a value not significantly different from 1.00. Control and pyelonephritic rats then received an intravenous infusion of $0.9 \% \mathrm{NaCl}$ containing $5 \mathrm{mU} / \mathrm{ml}$ aqueous $\mathrm{ADH}, 12-15 \mu \mathrm{Ci} / \mathrm{ml}\left[{ }^{3} \mathrm{H}\right]$ inulin, and $6 \mu \mathrm{Ci} / \mathrm{ml}\left[{ }^{14} \mathrm{C}\right]$ urea at $2.5 \mathrm{ml} / \mathrm{h}$. After a $1-\mathrm{h}$ equilibration, 20-40-min collections of urine were made under mineral oil in 1.0-ml syringes for determination of whole kidney clearance values. Two to six clearance periods were obtained in each rat. $150-\mu \mathrm{l}$ samples of arterial blood were collected in heparinized microhematocrit tubes from the femoral catheter at 30 -min intervals. Mean arterial blood pressure was measured every $30 \mathrm{~min}$ with a mercury manometer. Proximal and distal tubules ${ }^{2}$ were identified after injection of $50 \mu \mathrm{l}$ of a $5 \%$ solution of lissamine green dye (Roboz Surgical Instrument Co., Inc., Washington, D.C.) into the jugular vein. The use of lissamine green to identify proximal and distal nephron segments in pyelonephritic rats has been validated by previous workers $(11,13,14)$. No animal received more than $0.75 \mathrm{ml}$ of the dye solution and most received less than $0.50 \mathrm{ml}$. Tubular fluid samples were collected with silicon-coated acid-washed micropipettes (7-10 $\mu \mathrm{m}$ outside diameter). The average time of collection

\footnotetext{
2 In this study the "proximal tubule" is defined as that segment of the nephron extending from the glomerulus to the last convolution of the proximal tubule accessible to micropuncture; the "loop of Henle" is defined as the segment of the nephron between the last surface convolution of the proximal tubule and the earliest distal convolution accessible for micropuncture. As such the loop of Henle includes the pars recta and a short portion of the earliest distal tubule.
} 
was $2.3 \mathrm{~min}$ (range 1.3-3.8) for proximal tubular samples, and $3.0 \mathrm{~min}$ (range 1.0-5.1) for distal tubular samples. The fluid was collected at a rate that avoided changes in tubular diameter and maintained a column of Sudan black-colored castor oil, 5-10 tubule diameters long, stationary distal to the pipette tip. In most instances gentle suction was necessary to overcome the initial tip resistance and fluid then flowed spontaneously.

The following samples were obtained: (a) 28 late proximal and 17 distal tubular samples from seven intact control animals; $(b) 10$ late proximal and 29 distal tubular samples from five uninephrectomized control animals; and (c) 27 late proximal and 14 distal tubular samples from seven pyelonephritic animals. Bladder urine was simultaneously collected in all animals and in an additional three intact control animals that did not undergo micropuncture. Complete bladder emptying was assured by gently massaging the suprapubic area at the end of each collection period. The samples of tubular fluid were deposited under oil in siliconized dishes. A volume of $3 \mathrm{nl}$ was removed with a calibrated constriction pipette and diluted in $40 \mathrm{nl}$ of a solution of $1 \mathrm{mM}$ $\mathrm{NH}_{4} \mathrm{H}_{2} \mathrm{PO}_{4}-2 \mathrm{mM} \mathrm{CsNO}$ for measurement of sodium and potassium. The volume of the remainder of each sample was then measured in a calibrated quartz capillary tube and delivered into a counting vial containing $10 \mathrm{ml}$ of Aquasol solution (New England Nuclear, Boston, Mass.). The ${ }^{3} \mathrm{H}$ and ${ }^{14} \mathrm{C}$ activities were counted for $100 \mathrm{~min}$ in a Tri-Carb liquid scintillation spectrometer (model 3330, Packard Instrument Co., Inc., Downers Grove, Ill.). Appropriate correction was made for the crossover of ${ }^{14} \mathrm{C}$ into the ${ }^{3} \mathrm{H}$ channel. Only samples with total counts at least three times background were considered acceptable.

At the completion of the micropuncture studies, the kidney(s) were removed for tissue analysis and the animals were exsanguinated. The blood was collected into heparinized tubes and centrifuged, and the plasma was separated.

Hydrated animals. Because of the severe dehydration in the rats subjected to micropuncture, a separate series of clearance experiments was performed on four intact control and four pyelonephritic animals without water deprivation. Food was withdrawn $16 \mathrm{~h}$ before study as in the hydropenic group. The right jugular vein, femoral artery, and bladder were cannulated as described above under light ether anesthesia. The animals were then placed in a plastic restrainer, and permitted to recover from the anesthesia. At least $30 \mathrm{~min}$ after they were fully awake, each animal received an intravenous priming injection of $1.0 \mathrm{ml}$ of $0.9 \% \mathrm{NaCl}$ containing $30 \mu \mathrm{Ci}\left[{ }^{3} \mathrm{H}\right]$ methoxy-inulin and $5 \mu \mathrm{Ci}\left[{ }^{14} \mathrm{C}\right]$ urea (both from New England Nuclear). A sustaining solution of $0.9 \% \mathrm{NaCl}$ was then infused at $2.5 \mathrm{ml} / \mathrm{h}$. (In two of the pyelonephritic rats the sustaining solution was infused at $1.2 \mathrm{ml} / \mathrm{h}$ ). The latter contained $3 \mu \mathrm{Ci} / \mathrm{ml}\left[{ }^{3} \mathrm{H}\right]$ inulin, $1.5 \mu \mathrm{Ci} / \mathrm{ml}$ $\left[{ }^{14} \mathrm{C}\right]$ urea, and $5-8 \mathrm{mU} / \mathrm{ml}$ aqueous $\mathrm{ADH}$. After a 2 -h equilibration, three $30-\mathrm{min}$ clearance periods were obtained as described above, and at the conclusion of the third clearance period the animals were exsanguinated.

Tissue slice studies. Analyses of kidney slices were performed on four intact, five uninephrectomized control, and seven pyelonephritic rats. In all three groups the micropunctured left kidney, and, in the intact control group, the unmicropunctured right kidney as well, was removed after clamping of the renal artery and vein. The kidneys were snap-frozen in a solution of acetone-dry ice, weighed, and sectioned with a razor blade so as to obtain the entire papilla, and portions of the inner medulla, outer medulla and cortex. Each individual section was weighed and homogenized in $500 \mu \mathrm{l}$ of deionized distilled water with a Duall glass homogenizer (no. 20, Kontes Co., Vineland, N.J.).
TABLE I

Percent Water by Weight in Kidney Tissue Slices

\begin{tabular}{lccc}
\hline \multicolumn{1}{c}{ Tissue } & $\begin{array}{c}\text { Intact control } \\
\text { rats }\end{array}$ & $\begin{array}{c}\text { Uninephrectomized } \\
\text { control rats }\end{array}$ & $\begin{array}{c}\text { Pyelonephritic } \\
\text { rats }\end{array}$ \\
\hline & $\%$ & $\%$ & $\%$ \\
Cortex & $77.5 \pm 0.5$ & $77.3 \pm 1.5$ & $78.0 \pm 1.4$ \\
Outer medulla & $84.3 \pm 1.3$ & $81.8 \pm 0.7$ & $78.4 \pm 1.1$ \\
Inner medulla & $87.9 \pm 1.0$ & $85.9 \pm 1.1$ & $82.6 \pm 3.7$ \\
Papilla & $83.3 \pm 2.8$ & $87.9 \pm 2.0$ & $83.1 \pm 3.0$ \\
\hline
\end{tabular}

The homogenate was centrifuged at $4^{\circ} \mathrm{C}$ for 20 min at $800 \mathrm{~g}$ and the supernatant solution was removed and frozen for later analysis of sodium, potassium, and urea.

Analytic methods and calculations. Sodium and potassium concentrations in plasma, urine, and tissue homogenates were measured by flame photometry (Instrumentation Laboratory, Inc., model 143, Lexington, Mass.). Tubular fluid sodium and potassium concentrations were measured with a helium glow photometer (American Instrument Co., Travenol Laboratories, Inc., Silver Spring, Md.). With the helium-glow photometer, in our laboratory, the mean recovery of sodium was $101 \pm 6 \%$ (SD) $(n=58)$ for the range of $10-170 \mathrm{meq} / \mathrm{liter}$; the mean recovery of potassium was $101 \pm 7 \%$ (SD) $(n=62)$ for the range of $2-30 \mathrm{meq} / \mathrm{liter}$. Urea concentrations in plasma, urine, and tissue homogenates were determined by the method of Berthelot (15). Osmolality of plasma and urine samples was measured with a Wescor vapor pressure osmometer (Model-100, Wescor Inc., Logan, Utah). In tissue homogenates and tubular fluid samples osmolality was estimated by the equation [osm] $=1.86$ $[\mathrm{Na}+\mathrm{K}]+[$ urea] (16). By this equation, calculated tubular fluid-to-plasma osmolality ratio $\left[(\mathrm{TF} / \mathrm{P})_{\mathrm{osm}}\right]$ averaged $1.00 \pm$ 0.02 in 15 proximal tubules from four normal rats.

Standard clearance formulas were utilized for whole kidney measurements. Single nephron glomerular filtration rate (SNGFR) was calculated as (TF/P) in $\times$ tubular flow rate and expressed as the average of the individual animal means. Fractional delivery of urea, sodium and water to the site of puncture was calculated as $\left[(\mathrm{TF} / \mathrm{P})_{\text {urea }} /(\mathrm{TF} / \mathrm{P})_{\text {In }}\right] \times 100$, $\left[(\mathrm{TF} / \mathrm{P})_{\mathrm{Na}} /(\mathrm{TF} / \mathrm{P})_{\mathrm{In}}\right] \times 100$, and $(\mathrm{P} / \mathrm{TF})_{\text {In }} \times 100$, respectively. The results obtained in tissue homogenates were expressed per kilogram of tissue $\mathrm{H}_{2} \mathrm{O}$. The amount of tissue water in the kidney sections was determined in separate experiments from the difference between wet and dry weights. For this purpose 11 intact, 15 uninephrectomized, and 18 pyelonephritic rats were given $\mathrm{ADH}$ in oil, dehydrated for $16 \mathrm{~h}$, and then sacrificed. Their kidneys were removed and sectioned exactly as described above. The different sections were then weighed before and after dehydration in an oven at $80^{\circ} \mathrm{C}$ for $48 \mathrm{~h}$. The average percentages of tissue water used in computation of the slice data are presented in Table I for the different sections of kidneys from each group of rats.

All results are reported as means $\pm \mathrm{SE}$. Statistical analysis used Student's $t$ test for unpaired data. The level of significance was set at $P<0.05$.

\section{RESULTS}

Maximal urinary concentrating ability. Individual and mean values of $U_{\max }$ achieved after $36 \mathrm{~h}$ of water deprivation and ADH administration are shown in Fig. 2 for seven control rats with intact kidneys, 


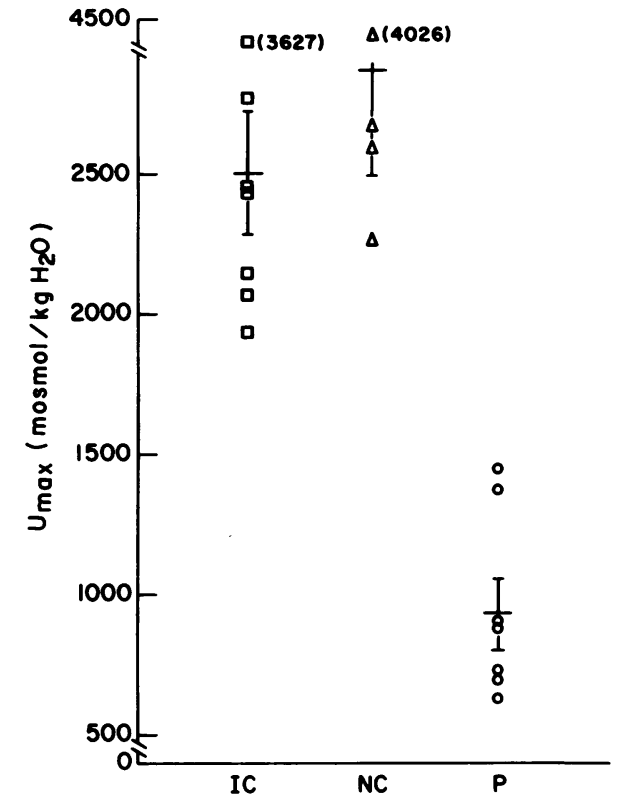

FIGURE 2 Maximal urinary concentration $\left(U_{\max }\right)$ in seven control animals with intact kidneys (IC), four uninephrectomized control rats (NC), and seven animals with a single pyelonephritic kidney (P).

four uninephrectomized control rats, and seven animals with a single pyelonephritic kidney. The capacity to concentrate urine was similar in both groups of control animals. There was no significant difference between the mean $U_{\max }$ values of $2,501 \pm 217$ and $2,874 \pm 392$ mosmol/ $/ \mathrm{kg} \mathrm{H}_{2} \mathrm{O}$ observed in control animals with two and one kidney(s), respectively. By contrast, all the pyelonephritic rats demonstrated a defect in concentrating ability and, for the group, the mean $U_{\max }$ of
$929 \pm 130$ mosmol/ $\mathrm{kg} \mathrm{H}_{2} \mathrm{O}$ was significantly lower than that obtained in either control group $(P<0.001)$.

Whole kidney function data. Mean values for plasma osmolality, plasma urea, plasma nonurea solute, and arterial hematocrit are presented in Table II for all control and pyelonephritic rats in which whole kidney function was measured.

Plasma osmolality was significantly increased and arterial hematocrit was significantly decreased in both hydropenic and hydrated animals with pyelonephritis. Since plasma nonurea solute values were similar in all groups, the increase in plasma osmolality was accounted for by the azotemia of the pyelonephritic rats. The difference in plasma osmolality, plasma urea, and hematocrit values observed between hydropenic and hydrated rats reflected the difference in the state of hydration of the two series of animals. Indeed, during the $16 \mathrm{~h}$ of water deprivation, intact and uninephrectomized control animals and pyelonephritic animals of the hydropenic series lost $6.6 \pm 0.9,6.9 \pm 0.7$, and $10.0 \pm 1.2 \%$ of body weight, respectively $(P<0.05$ compared to either control group)

The results of whole kidney function measurements are also presented in Table II for the same groups of animals. In the hydropenic rats, glomerular filtration rate (GFR) averaged $1.57 \pm 0.19 \mathrm{ml} / \mathrm{min}$ in the intact rats, $1.39 \pm 0.18 \mathrm{ml} / \mathrm{min}$ in the uninephrectomized control group, and $0.30 \pm 0.07 \mathrm{ml} / \mathrm{min}$ in the pyelonephritic group $(P<0.005$ compared to either control group). In the hydrated rats GFR averaged $1.51 \pm 0.13$ $\mathrm{ml} / \mathrm{min}$ in control and $0.65 \pm 0.10 \mathrm{ml} / \mathrm{min}$ in pyelonephritic animals $(P<0.005)$.

In both series of experiments, $(\mathrm{U} / \mathrm{P})_{\text {In }}$ and $(\mathrm{U} / \mathrm{P})_{\text {osm }}$ ratios were significantly greater in control than in pyelonephritic rats, reflecting greater fractional water

TABLE II

Plasma Osmolality, Urea and Nonurea Solute, Arterial Hematocrit, and Whole Kidney Function Data in Control and Pyelonephritic Rats

\begin{tabular}{|c|c|c|c|c|c|c|c|c|}
\hline & \multicolumn{5}{|c|}{ Hydropenic animals } & \multicolumn{3}{|c|}{ Hydrated animals } \\
\hline & $\begin{array}{l}\text { Intact } \\
\text { control }\end{array}$ & $P$ & Pyelonephritis & $P$ & $\begin{array}{l}\text { Uninephrectomized } \\
\text { control }\end{array}$ & Control & $\boldsymbol{P}$ & Pyelonephritis \\
\hline No. animals & $10^{*}$ & & $7 \ddagger$ & & 5 & 4 & & 4 \\
\hline $\mathbf{P}_{\text {osm }}$, mosmol/kg & $298 \pm 5$ & $<0.02$ & $323 \pm 7$ & NS & $309 \pm 8$ & $290 \pm 2$ & $<0.005$ & $312 \pm 4$ \\
\hline $\mathbf{P}_{\text {urea }}$, mmolliter & $12.5 \pm 1.4$ & $<0.001$ & $32.3 \pm 7.2$ & $<0.001$ & $12.4 \pm 1.7$ & $9.2 \pm 0.9$ & $<0.05$ & $24.3 \pm 5.7$ \\
\hline $\begin{array}{l}\mathrm{P}_{\text {nonurea solute }} \\
\text { mosmol/kg } \\
\text { Hematocrit \% }\end{array}$ & $\begin{array}{l}284 \pm 6 \\
46.9 \pm 1.1\end{array}$ & $\begin{array}{c}\text { NS } \\
<0.025\end{array}$ & $\begin{array}{l}288 \pm 14.6 \\
40.9 \pm 1.8\end{array}$ & $\begin{array}{c}\text { NS } \\
<0.001\end{array}$ & $\begin{array}{r}296 \pm 6.5 \\
48.4 \pm 1.1\end{array}$ & $\begin{array}{r}281 \pm 2.2 \\
44.0 \pm 0.7\end{array}$ & $\begin{array}{c}\text { NS } \\
<0.02\end{array}$ & $\begin{array}{r}287.5 \pm 2.2 \\
36.6 \pm 2.3\end{array}$ \\
\hline $\begin{array}{l}\text { Hematocrit, } \% \\
\text { Clearance of inulin, }\end{array}$ & $40.0 \pm 1.1$ & & $40.9 \pm 1.0$ & & & & & $30.0-2.0$ \\
\hline $\mathrm{ml} / \mathrm{min}$ & $1.57 \pm 0.19$ & $<0.005$ & $0.30 \pm 0.07$ & $<0.005$ & $1.39 \pm 0.18$ & $1.51 \pm 0.13$ & $<0.001$ & $0.65 \pm 0.10$ \\
\hline$(\mathrm{U} / \mathrm{P})_{\mathrm{In}}$ & $239 \pm 46.9$ & $<0.02$ & $42.6 \pm 9.2$ & $<0.02$ & $222 \pm 44$ & $67.3 \pm 7.1$ & $<0.001$ & $16.9 \pm 2.2$ \\
\hline$(\mathrm{U} / \mathrm{P})_{\mathrm{osm}}$ & $5.34 \pm 0.54$ & $<0.001$ & $1.57 \pm 0.11$ & $<0.001$ & $5.32 \pm 0.42$ & $4.90 \pm 0.43$ & $<0.001$ & $1.83 \pm 0.15$ \\
\hline $\mathbf{F} \mathbf{E}_{\text {urea }}, \%$ & $38.4 \pm 6.8$ & NS & $26.8 \pm 5.1$ & NS & $45.6 \pm 10.5$ & $102.3 \pm 7.6$ & $<0.05$ & $78 \pm 5.4$ \\
\hline
\end{tabular}

* Osmolality measurements were obtained in 7 of 10 animals.

\$ Urine measurements were obtained in 6 of the 7 animals. 


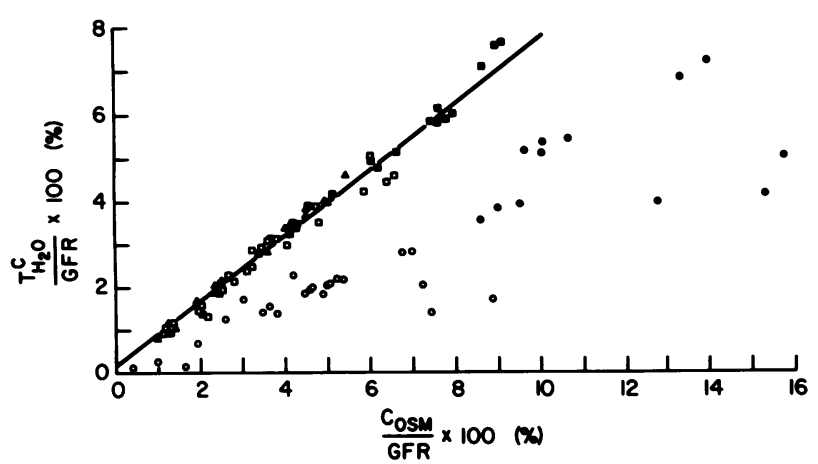

FIGURE 3 Relationship between free water reabsorption per $100 \mathrm{ml}$ GFR in intact control animals (squares), in uninephrectomized control animals (triangles), and in pyelonephritic animals (circles). Closed symbols indicate hydrated animals and open symbols indicate hydropenic animals. Equation of regression line for control animals: $y=0.78 x+0.08(r=0.99, P<0.001)$

reabsorption and concentrating capacity, respectively. Fractional urea excretion was not significantly different in rats with pyelonephritis and in control rats.

The ability to reabsorb solute-free water as a function of solute clearance is shown in Fig. 3, where fractional free water reabsorption, $\left(\mathrm{T}_{\mathrm{H}_{2} \mathrm{O}}^{\mathrm{C}} \mathrm{GFR}\right) \times 100$, is plotted as a function of fractional osmolal clearance $\left(\mathrm{C}_{\mathrm{OSM}} / \mathrm{GFR}\right)$ $\times 100$. The values for both hydropenic and hydrated control rats were distributed along a straight line, whereas all values in the rats with pyelonephritis fell well below the control line. Thus, the pyelonephritic animals demonstrated a subnormal fractional free water reabsorption at any given level of fractional osmolal clearance.

Fig. 4 illustrates the relationship between fractional urea excretion $\left(\mathrm{FE}_{\mathrm{urea}}\right)$ and the fraction of filtered water excreted $\left(\mathrm{FE}_{\mathrm{H}_{2} \mathrm{O}}\right)$. The mean value for $\mathrm{FE}_{\mathrm{H}_{2} \mathrm{O}}$ was significantly greater in the uremic rats than in the control rats $(2.97 \pm 0.69 \%$ vs. $0.61 \pm 0.15 \%, P<0.001)$, and all but one pyelonephritic rat had values above the maximum value of $2 \%$ observed in the control groups. In both control groups and in the pyelonephritic group, a correlation between $\mathrm{FE}_{\text {urea }}$ and $\mathrm{FE}_{\mathrm{H}_{2} \mathrm{O}}$ was evident. However, the relationship was clearly different in control and pyelonephritic rats, suggesting an altered intranephronal handling of urea.

Micropuncture data. Mean arterial blood pressure was not different between the control and the pyelonephritic groups of rats subjected to micropuncture $(118.6 \pm 4.6 \mathrm{~mm} \mathrm{Hg}$ for intact control, $107.0 \pm 8.4 \mathrm{~mm} \mathrm{Hg}$ for uninephrectomized control, and $108.3 \pm 5.7 \mathrm{~mm} \mathrm{Hg}$ for pyelonephritic animals). Within each group, SNGFR was not different when determined from proximal or distal tubular puncture sites. But, in both groups with a single kidney, SNGFR was significantly greater $(P<0.05)$ than in the control group with

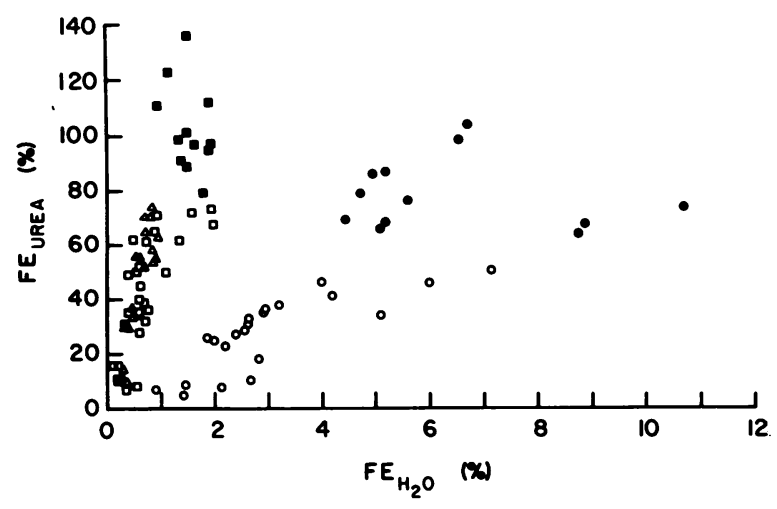

FIGURE 4 Relationship between fractional excretion of urea $\left(\mathrm{FE}_{\text {urea }}\right)$ and fractional excretion of $\mathrm{H}_{2} \mathrm{O}\left(\mathrm{FE}_{\mathrm{H}_{2} \mathrm{O}}\right)$ in control and pyelonephritic animals. Symbols are defined in Fig. 3.

two intact kidneys $(88.0 \pm 10.8 \mathrm{nl} / \mathrm{min}$ for uninephrectomized control and $71.5 \pm 14.4 \mathrm{nl} / \mathrm{min}$ for pyelonephritic, vs. $35.6 \pm 3.8 \mathrm{nl} / \mathrm{min}$ for intact control animals). There was no significant difference in values for SNGFR between uninephrectomized control and pyelonephritic animals.

Fig. 5 presents a segmental analysis of the fraction of filtered water, sodium, and urea delivered late in the proximal tubule and early in the distal tubule. Fractional water delivery and fractional sodium delivery were closely comparable and not significantly different in pyelonephritic and control groups, demonstrating continuous sodium and water reabsorption along the nephron. Thus, because of the increased SNGFR, absolute water delivery at both nephron sites

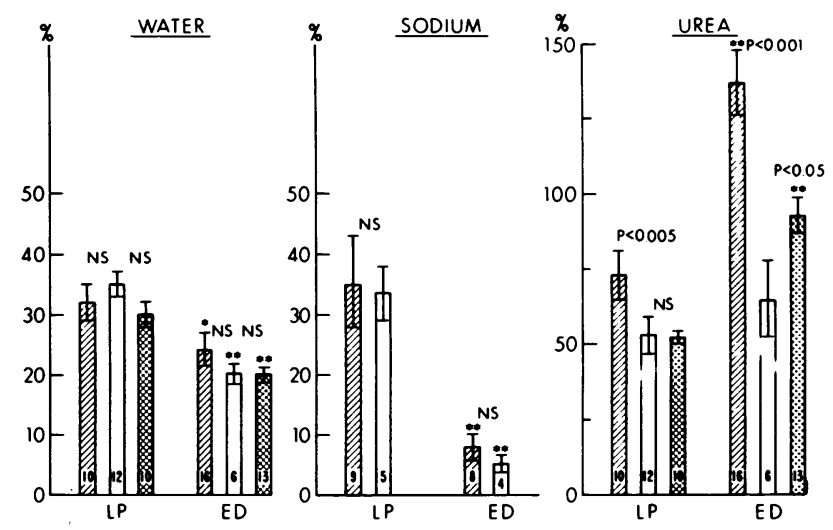

Figure 5 Fractional deliveries of water, sodium, and urea to the late proximal convoluted tubule (LP), and early distal convoluted tubule (ED) in intact control animals (hatched bars), pyelonephritic animals (open bars), and uninephrectomized control animals (cross-hatched bars). Numbers within the bars represent observations. *ED value significantly different from LP value $(P<0.025)$; ${ }^{* *} \mathrm{ED}$ value significantly different from LP value $(P<0.001)$. 


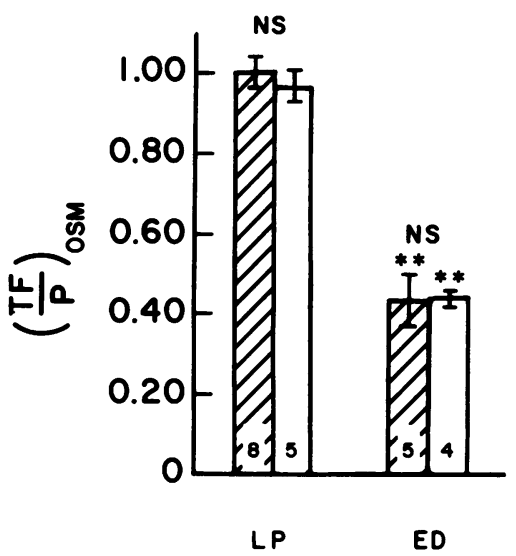

FIGURE 6 Mean $(\mathrm{TF} / \mathrm{P})_{\text {osm }}$ ratios in the late proximal convoluted tubule and the early distal convoluted tubule in intact control animals (hatched bars) and pyelonephritic animals (open bars). Symbols are defined in Fig. 5 .

was twice as great in uninephrectomized control and in pyelonephritic animals as in intact control animals.

Fractional urea delivery from the proximal tubule was greater in intact control than in uninephrectomized or pyelonephritic animals: $73 \pm 8 \%$ vs. $52 \pm 2 \%$ and $53 \pm 3 \%$, respectively $(P<0.005)$. Both groups of control animals demonstrated significant addition of urea in the loop of Henle, as urea delivery to the early distal tubule rose to $137 \pm 11 \%$ and $93 \pm 6 \%$ of the filtered load in intact and uninephrectomized control animals $(P<0.001$ for each group compared to the late proximal tubule value). In contrast, fractional delivery of urea in the early distal tubule of pyelonephritic animals was $65 \pm 13 \%$, a value not significantly different from that observed in the late proximal tubule of the same group of animals and significantly less than that observed in the early distal tubule of each control group.

Mean $(\mathrm{TF} / \mathrm{P})_{\text {osm }}$ ratios in the late proximal tubule and the early distal tubule are shown in Fig. 6. The late proximal tubular fluid was iso-osmotic in intact control and in pyelonephritic rats. In contrast, $(\mathrm{TF} / \mathrm{P})_{\text {osm }}$ ratios in early distal tubular samples were reduced significantly $(P<0.001)$ and to an equal degree in both normal and pyelonephritic animals $(0.43 \pm 0.07$ and $0.44 \pm 0.02$, respectively). Thus, the loop of Henle of superficial nephrons in diseased and normal kidneys demonstrates the same capacity to dilute the tubular fluid, although the absolute volume of tubular fluid per nephron delivered to the loop was approximately twice as great in the pyelonephritic rats as in the control rats.

Tissue slice data. The results from tissue slice analyses are presented in Figs. 7 and 8 for micropunctured pyelonephritic kidneys and for micropunctured and unmicropunctured kidneys from control animals. In both groups of control kidneys a distinct corticopapillary gradient for total tissue water solute concentration was observed. In contrast, the pyelonephritic kidneys exhibited no such gradient (Fig. 7), and these results are unchanged even if the solute content is expressed per unit dry weight.

Fig. 8 depicts the fraction of tissue water solute contributed by urea in cortex, outer medulla, inner medulla, and papilla. In the control animals this fraction rose from cortex to papilla; the increment was somewhat greater in the unmicropunctured kidneys than in the micropunctured kidneys. In the pyelonephritic kidneys, the fractional contribution of urea to cortical tissue solute concentration was greater than in the control kidneys (a reflection of the increased plasma urea in the pyelonephritic animals); however, this fraction remained nearly constant from cortex to papilla and was significantly less in the inner medulla and papilla than in either group of control kidneys $(P<0.001)$, a finding consistent with previous observations by Gonick et al. (17).

\section{DISCUSSION}

The generation and maintenance of a concentration gradient from cortex to papilla is essential for the ability of the normal kidney to raise the osmotic pressure of urine above that of plasma. According to current theories $(8,9,18,19)$, the creation of this gradient is accomplished by the removal of solute from the ascending limb of Henle's loop, ${ }^{3}$ and from the inner medullary and papillary collecting ducts, with substantial trapping of this solute within the interstitial fluid of the inner medulla and papilla. Under the influence of $\mathrm{ADH}$, the cortical and medullary collecting ducts become highly permeable to water; water diffuses down its chemical concentration gradient from tubular fluid to interstitial fluid; and in consequence of this diffusion of water, the concentration of urea in the tubular fluid increases. In the papillary region of the collecting duct (perhaps under the influence of $\mathrm{ADH}$ ), the permeability to urea increases $(23,24)$ and there is further diffusion of urea from collecting duct fluid into the interstitial fluid of the inner medulla. During antidiuresis, urea residing within the medullary interstitial pool enters the pars recta (25) and the ascending limb of Henle's loop, and as a result, more urea may enter the distal tubule in the normal kidney than is initially filtered $(12,26)$. As long as the plasma flow through the ascending vasa recta

\footnotetext{
${ }^{3}$ There is general agreement that this is accomplished by active transport of chloride in the thick ascending limb (20), but there is controversy concerning the possibility of active sodium transport by the thin ascending limb $(21,22)$.
} 
is not too great, this recycling of urea serves to maintain a corticopapillary concentration gradient for urea in the inner regions of the kidney.

The data obtained from the normal kidneys of both control groups fit well within the framework of the foregoing theoretical formulation. In the loop of Henle of micropunctured superficial nephrons, sodium and water were reabsorbed, urea was added, and the $(\mathrm{TF} / \mathrm{P})_{\text {osm }}$ ratio fell. The tissue slice data demonstrated a corticopapillary solute (and urea) gradient. Moreover, the proportion of the total tissue water solute contributed by urea increased from cortex to papilla as predicted by the model.

The experimental rats exhibited histologic changes typical of chronic pyelonephritis (27), as well as the characteristic abnormalities of urinary concentrating ability, a marked decrement in $\mathrm{U}_{\max }$ and $\mathrm{T}_{\mathrm{H}_{2} \mathrm{O}}^{\mathrm{O}}$ GFR $(1,14,28,29)$.

While $\mathrm{U}_{\max }$ and $\mathrm{T}_{\mathrm{H}_{2} \mathrm{O}} \mathrm{G}$ GFR are, in part, interdependent, they measure different functions. $\mathrm{T}_{\mathrm{H}_{2} \mathrm{O}}$ GFR is that fraction of the glomerular filtrate returned to the plasma as solute-free water. As such it measures the amount of water conserved by the collecting duct in the transition from an iso-osmotic tubular fluid to a hypertonic urine. If the tubular fluid enters the

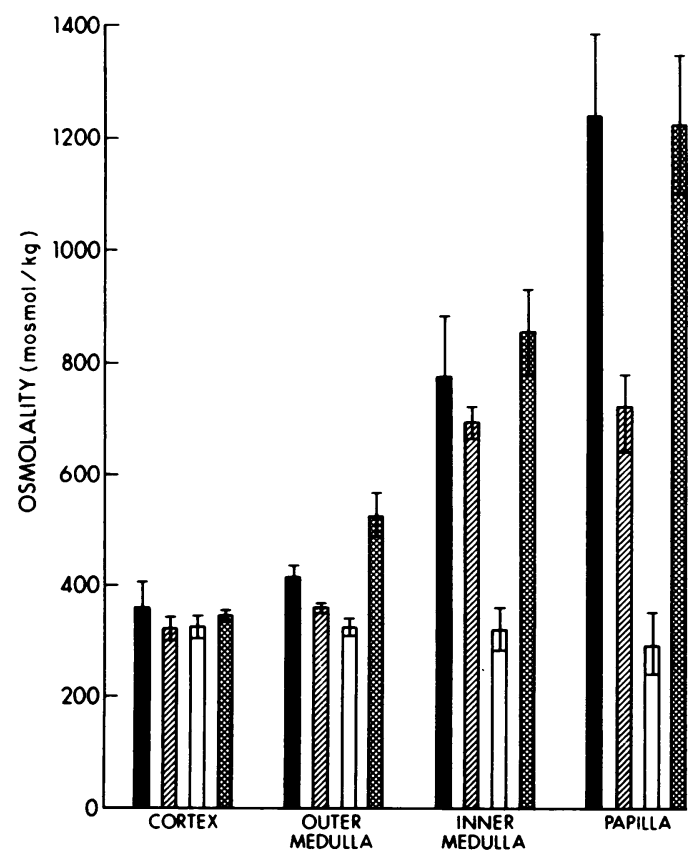

FIGURE 7 Total solute concentration in tissue water of cortical, outer and inner medullary, and papillary slices from four control unmicropunctured kidneys from intact control animals (stippled bars), four control micropunctured kidneys from intact control animals (hatched bars), six micropunctured kidneys from pyelonephritic animals (open bars), and five micropunctured kidneys from uninephrectomized control animals (cross-hatched bars).

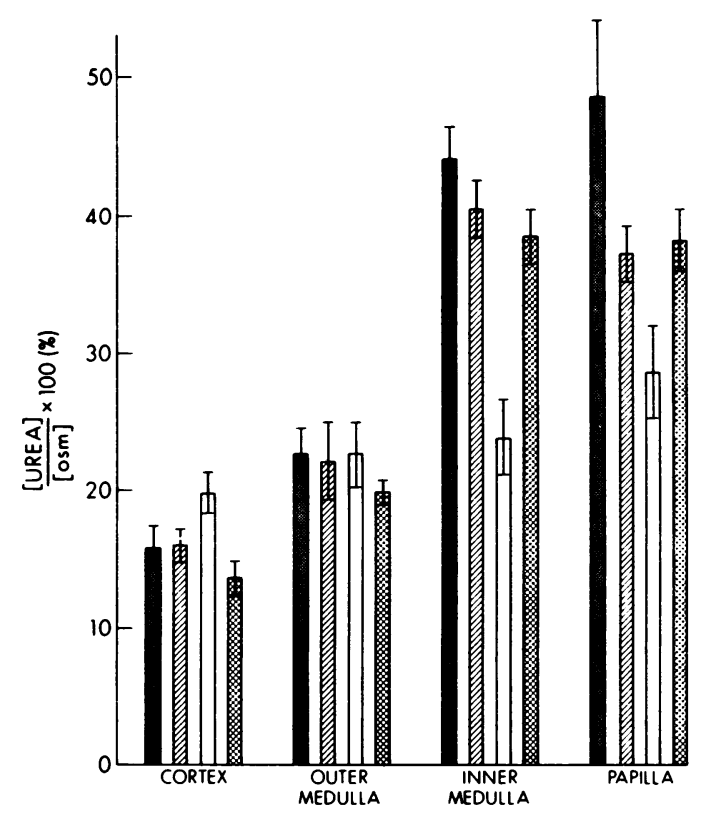

FIGURE 8 Urea concentration as a percent of total solute concentration in tissue water of kidney slices from control and pyelonephritic rats. The number of animals studied and symbols are described in Fig. 7.

collecting duct hypotonic to plasma $(30,31)$ in great volume, as in the hypertrophied nephrons of both the unilaterally nephrectomized control group and the pyelonephritic group, ${ }^{4}$ the point at which the tubular fluid achieves isotonicity could, in theory, be shifted distally towards the tip of the renal papilla. This down-stream translocation of the iso-osmotic point would have two principal effects:

(a) $\mathrm{T}_{\mathrm{H}_{2} \mathrm{O}}^{\mathrm{C}} / \mathrm{GFR}$ would be reduced and may even become negative if isotonicity were not achieved by the time the tubular fluid reaches the ducts of Bellini, as in vasopressin-resistant hyposthenuria $(5,6)$.

(b) Since the absolute quantity of water reabsorbed is greater when the tubular fluid is converted from a hypotonic to an isotonic solution than from an isotonic to a maximally hypertonic solution, a "downstream" shift in the point at which isotonicity is reached could lead to an inappropriate dilution of the inner medullary and papillary interstitial fluid. The

\footnotetext{
${ }^{4}$ The observation that the early distal $(\mathrm{TF} / \mathrm{P})_{\mathrm{osm}}$ ratios for control and pyelonephritic animals were identical (Fig. 6) provides evidence that the diluting capacity of superficial uremic nephrons was well preserved. This finding agrees with prior clinical observations (4). The volume of free water in excess of iso-osmolal tubular fluid delivered to the distal nephron is given by tubular flow rate $X\left[1-(T F / P)_{\text {osm }}\right]$. In pyelonephritic nephrons, distal tubular flow rate is approximately twice the value found in normal nephrons; thus, free water load per nephron is also approximately twice that of normal nephrons.
} 
effect of the latter would be to reduce the maximum value for urinary osmolality.

It thus becomes difficult to draw specific conclusions about the physiologic basis of the concentrating defect in uremia from an analysis of values for $\mathrm{T}_{\mathrm{H}_{2} \mathrm{O}}^{\mathrm{O}} / \mathrm{GFR}$ and $U_{\max }$ alone, since a reduction of values for both could result from an increase in the volume of hypotonic tubular fluid delivered to the inner medulla.

The present data demonstrated that at equal values for fractional urea excretion, the pyelonephritic animals excreted a substantially greater fraction of their filtered water than did either of the two control groups. Since the values for SNGFR and for distal delivery of tubular fluid were no greater in the pyelonephritic than the uninephrectomized animals, these differences are unlikely to be due either to hyperfiltration or to increased tubular flow rates per se.

The data obtained from micropuncture of superficial nephrons of pyelonephritic kidneys demonstrated that sodium, water, and urea $^{5}$ were avidly reabsorbed in the proximal convoluted tubule. The unusually avid reabsorption of water and sodium presumably is a reflection of the severe extracellular fluid volume contraction associated with the extreme degrees of weight loss brought about by dehydration $(11,13$, $32,33)$.

Comparison of values from the end of the accessible portion of the proximal tubule and from the early distal tubule demonstrated that fractional reabsorptions of sodium and water were closely comparable in normal and pyelonephritic rats, a finding consistent with prior observations $(11,13,14)$. However, in contrast to the evidence for net addition of substantial amounts of urea to the loop of Henle in kidneys from both intact control and uninephrectomized control rats, no significant entry of urea into Henle's loop was apparent in the pyelonephritic kidneys. Thus the intrarenal urea cycle was interrupted in the superficial nephrons of the pyelonephritic kidneys. This same observation has recently been made by Armsen et al. (34).

Increased tubular flow rates cannot be invoked to explain the interruption in urea recycling. Indeed, SNGFR and tubular flow rate were increased to a comparable degree in uninephrectomized controls and pyelonephritic rats, but only the latter animals failed to recycle urea. Moreover, the analysis of kidney slices demonstrated a markedly decreased concentration of urea in the inner medullary and papillary tissue water

\footnotetext{
${ }^{5}$ The fact that fractional delivery of urea out of the proximal tubule was greater in the normal control rats than in either of the other two groups, while fractional delivery of water was closely comparable among the three groups, is not readily explicable. The possibility that this phenomenon is due to a decrease in the reflection coefficient for urea in hypertrophied nephrons with supernormal values for SNGFR remains to be examined.
}

in pyelonephritic rats compared not only to intact control rats but also to the uninephrectomized control rats; and the latter animals maintained as steep a corticopapillary gradient both for total solute and for urea as the intact control rats. In contrast, the pyelonephritic kidneys established neither a total solute nor a urea gradient from cortex to papilla. Finally, the uninephrectomized control rats achieved values for $U_{\max }$ as high as those for the intact control animals, while the pyelonephritic group exhibited a markedly impaired ability to concentrate the final urine.

The present studies show that: $(a)$ the pyelonephritic kidneys fail to concentrate the urine osmotically to a maximal degree and fail to conserve free water maximally; and $(b)$ these functional defects are associated with a failure to accumulate solutes in the interstitial fluid water and with an interruption of the intrarenal recycling of urea. The explanation for the latter phenomenon is not evident from the present data and, in theory, could be due to one or more of the following events:

(a) Reduction in the permeability of the pars recta and the ascending limb of Henle to urea with a resultant decrease in urea entry into the loop.

(b) Diminished responsiveness to $\mathrm{ADH}$ in the cortical collecting tubule with impairment of water diffusion from this segment of the nephron. The latter would reduce the degree to which intratubular urea is concentrated and thereby retard the diffusion of urea from the papillary collecting duct into the interstitial fluid.

(c) Delivery of increased quantities of hypotonic tubular fluid downstream beyond the cortical collecting tubule, with failure to achieve osmotic equilibration with the surrounding interstitial fluid whatever the responsiveness to $\mathrm{ADH}$. Urea diffusion would thereby be retarded.

(d) Increase in the rate of plasma flow through the ascending vasa recta resulting in a "medullary washout" of urea and a resultant failure either to accumulate interstitial fluid solute or to recycle urea into the pars recta and ascending limb of Henle. The latter could occur even if the permeability to urea were unmodified and the tubular response to ADH were unimpaired.

Whatever the mechanism, the present study demonstrates that the intrarenal handling of urea is disordered and that the normal corticopapillary solute gradient is obliterated within the pyelonephritic kidney. This must inevitably lead to a concentrating defect.

\section{ACKNOWLEDGMENTS}

The authors are grateful to Pat Pellicone and Kathy Michael for secretarial assistance.

These studies were supported by grants 5 PO1-AM-16281 and 5 TOI-HL 05928 from the National Institutes of Health, by the Florence and Theodore Baumritter Kidney Center, 
by grant 74923 from the American Heart Association, and by the New York State Kidney Disease Institute.

\section{REFERENCES}

1. Seldin, D. W., N. W. Carter, and F. C. Rector, Jr. 1971. Consequences of renal failure and their management. In Diseases of the Kidney. M. B. Strauss and L. G. Welt, editors. Little, Brown and Company, Boston, Mass. 2nd edition. 211-272.

2. Schrier, R. W., and T. Berl. 1975. Nonosmolar factors affecting renal water excretion. N. Engl. J. Med. 292: 81-88, 141-145.

3. Dorhout Mees, E. J. 1959. Role of osmotic diuresis in impairment of concentrating ability in renal disease. Br. Med. J. 1: 1156-1158.

4. Kleeman, C. R., D. A. Adams, and M. H. Maxwell. 1961. An evaluation of maximal water diuresis in chronic renal disease. I. Normal solute intake. J. Lab. Clin. Med. 58: $169-184$.

5. Tannen, R. L., E. M. Regal, M. J. Dunn, and R. W. Schrier. 1969. Vasopressin-resistant hyposthenuria in advanced chronic renal disease. N. Engl. J. Med. 280: 1135-1141.

6. Holliday, M. A., T. J. Egan, C. R. Morris, A. S. Jarrah, and J. L. Harrah. 1967. Pitressin-resistant hyposthenuria in chronic renal disease. Am. J. Med. 42: 378-387.

7. Carriere, S., N. L. M. Wong, and J. H. Dirks. 1973. Redistribution of renal blood flow in acute and chronic reduction of renal mass. Kidney Int. 3: 364-371.

8. Kokko, J. P., and F. C. Rector, Jr. 1972. Countercurrent multiplication system without active transport in inner medulla. Kidney Int. 2: 214-223.

9. Stephenson, J. L. 1972. Concentration of urine in a central core model of the renal counterflow system. Kidney Int. 2: 85-94.

10. Imai, M., and J. P. Kokko. 1974. Sodium chloride, urea, and water transport in the thin ascending limb of Henle. Generation of osmotic gradients by passive diffusion of solutes. J. Clin. Invest. 53: 393-402.

11. Lubowitz, H., M. L. Purkerson, and N. S. Bricker. 1966. Investigation of single nephrons in the chronically diseased (pyelonephritic) kidney of the rat using micropuncture techniques. Nephron. 3: 73-83.

12. Lassiter, W. E., C. W. Gottschalk, and M. Mylle. 1961. Micropuncture study of net transtubular movement of water and urea in nondiuretic mammalian kidney. Am. J. Physiol. 200: 1139-1147.

13. Bank, N., and H. S. Aynedjian. 1966. Individual nephron function in experimental bilateral pyelonephritis. I. Glomerular filtration rate and proximal tubular sodium, potassium, and water reabsorption. J. Lab. Clin. Med. 68: 713-727.

14. Bank, N., and H. S. Aynedjian. 1966. Individual nephron function in experimental pyelonephritis. II. Distal tubular sodium and water reabsorption and the concentrating defect. J. Lab. Clin. Med. 68: 728-739.

15. Mattenheimer, H. 1970. Micromethods for the Clinical and Biochemical Laboratory. Ann Arbor Science Publishers, Inc., Ann Arbor, Mich. 2nd edition. 126-127.
16. Scientific Tables. 1970. K. Diem and C. Lentner, editors. Ciba-Geigy Ltd., Basel, Switzerland. 7th edition. 273.

17. Gonick, H. C., G. Goldberg, M. E. Rubini, and L. B. Guze. 1965. Functional abnormalities in experimental pyelonephritis. I. Studies of concentrating ability. Nephron. 2: 193-206.

18. Pennell, J. P., F. B. Lacy, and R. L. Jamison. 1974. An in vivo study of the concentrating process in the descending limb of Henle's loop. Kidney Int. 5: 337-347.

19. Pennell, J. P., V. Sanjana, N. R. Frey, and R. L. Jamison. 1975. The effect of urea infusion on the urinary concentrating mechanism in protein-depleted rats.J. Clin. Invest. 55: 399-409.

20. Rocha, A. S., and J. P. Kokko. 1973. Sodium chloride and water transport in the medullary thick ascending limb of Henle. Evidence for active chloride transport. J. Clin. Invest. 52: 612-623.

21. Marsh, D. J. 1970. Solute and water flows in thin limbs of Henle's loop in the hamster kidney. Am. J. Physiol. 218: 824-831.

22. Marsh, D. J., and S. P. Azen. 1975. Mechanism of $\mathrm{NaCl}$ reabsorption by hamster thin ascending limbs of Henle's loop. Am. J. Physiol. 228: 71-79.

23. Morgan, T., and R. W. Berliner. 1968. Permeability of the loop of Henle, vasa recta, and collecting duct to water, urea, and sodium. Am. J. Physiol. 215: 108-115.

24. Rocha, A. S., and J. P. Kokko. 1974. Permeability of medullary nephron segments to urea and water: Effect of vasopressin. Kidney Int. 6: 379-387.

25. Kawamura, S., and J. P. Kokko. 1976. Urea secretion by the straight segment of the proximal tubule.J. Clin. Invest. 58: $604-612$.

26. Armsen, T., and H. W. Reinhardt. 1971. Transtubular movement of urea at different degrees of water diuresis. Pflügers Arch. Eur. J. Physiol. 326: 270-280.

27. Heptinstall, R. H. 1974. Pathology of the Kidney. Little, Brown and Co., Boston. 2nd edition. 877-928.

28. Bricker, N. S., R. R. Dewey, H. Lubowitz, J. Stokes, and T. Kirgensgaard. 1959. Observations on the concentrating and diluting mechanisms of the diseased kidney. J. Clin. Invest. 38: 516-523.

29. Bricker, N. S., S. W. Kime, Jr., P. A. F. Morrin, and T. Orlowski. 1960. The influence of glomerular filtration rate, solute excretion and hydration on the concentrating mechanism of the experimentally diseased kidney in the dog. J. Clin. Invest. 39: 864-875.

30. Woodhall, P. B., and C. C. Tisher. 1973. Response of the distal tubule and cortical collecting tubule to vasopressin in the rat. J. Clin. Invest. 52: 3095-3108.

31. Gross, J. B., M. Imai, and J. P. Kokko. 1975. A functional comparison of the cortical collecting tubule and the distal convoluted tubule. J. Clin. Invest. 55: 1284-1294.

32. Hayslett, J. P., M. Kashgarian, and F. H. Epstein. 1968. Functional correlates of compensatory renal hypertrophy. J. Clin. Invest. 47: 774-782.

33. Weiner, M. W., E. J. Weinman, M. Kashgarian, and J. P. Hayslett. 1971. Accelerated reabsorption in the proximal tubule produced by volume depletion. J. Clin. Invest. 50: $1379-1385$.

34. Armsen, T. R., R. Joppich, G. Schubert, and H. H. Edel. 1975. Single nephron study of intrarenal urea handling in experimental pyelonephritis. Res. Exp. Med. 165: $141-152$. 